EXTENDED REPORT

\title{
Baseline IOP predicts selective laser trabeculoplasty success at 1 year post-treatment: results from a randomised clinical trial
}

\author{
W G Hodge, K F Damii, W Rock, R Buhrmann, A M Bovell, Y Pan
}

Br J Ophthalmol 2005;89:1157-1160. doi: 10.1136/bjo.2004.062414

See end of article for authors' affiliations

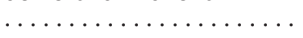

Correspondence to: Dr William G Hodge, The University of Ottawa Eye Institute, 501 Smyth Road, OHtawa, ON K1H 8L6

Canada; whodge@ ottawahospital.on.ca

Accepted for publication 1 March 2005
Background/aims: The efficacy and safety of selective laser trabeculoplasty (SLT) has been found to be equivalent to argon laser trabeculoplasty (ALT). Since SLT produces significantly less disturbance to the trabecular meshwork and is theoretically more repeatable than ALT, it has potential to replace ALT as the standard procedure to treat medically uncontrolled open angle glaucoma. This study's objective is to determine factors that predict successful SLT at 1 year post-treatment.

Methods: As part of a randomised clinical trial comparing the efficacy and safety of SLT to ALT, data on 72 SLT patients were collected, and successful SLT defined as having an SLT induced intraocular pressure (IOP) reduction of $\geqslant 20 \%$ at 1 year post-treatment follow up.

Results: 43 out of the 72 patients who had completed their 1 year follow up visit had an IOP reduction of $\geqslant 20 \%$ from baseline. No glaucoma risk factors studied predicted successful SLT. The amount of trabecular meshwork pigmentation was not a significant predictor. However, it was discovered that baseline IOP strongly predicted SLT success (odds ratio $=1.16 ; p=0.0001$ ).

Conclusion: SLT success was significantly predicted by baseline IOP but not by age, sex, other glaucoma risk factors, type of open angle glaucoma, or by degree of trabecular meshwork pigmentation.
A rgon laser trabeculoplasty (ALT) is a commonly used method to treat medically uncontrolled open angle glaucoma. Wise and Witter first introduced ALT in $1979^{1} ;$ it is believed that laser trabeculoplasty causes increased outflow facility by either or both of the following two mechanisms; (i) mechanical: by tightening the trabecular meshwork (TM) to open the adjacent, untreated intertrabecular spaces, ${ }^{2}$ and/or (ii) cellular: by inducing cell division and migration of macrophages to clear the TM debris. $^{34}$

ALT treatment has an impressive intraocular pressure (IOP) lowering effect in patients with elevated IOP, with previously reported early IOP reductions up to 35\% from baseline ${ }^{15-9}$; however, its effect declines with time. ${ }^{18^{10-12}}$ Ten year follow up data showed failure rate of $68-95 \%,{ }^{10}{ }^{11}$ and repeat ALT was generally perceived as ineffective at maintaining normal IOP as the rate of 1 year success (IOP less than $3 \mathrm{~mm}$ from baseline) is $21 \% .^{13}{ }^{14}$ The high long term failure rate of ALT could be explained by the fact that ALT causes detrimental disruption to the microstructure of the TM, and excessive TM damage determines treatment failure. Histopathological studies revealed remarkable uveoscleral meshwork destruction post-ALT treatment with coagulative tissue necrosis and fragmented cells, ${ }^{15}$ crater formation, ${ }^{16}$ heat damaged collagen fibres in tissues, ${ }^{16}{ }^{17}$ and membranes surrounding the argon laser spots formed by migrating endothelial cells. ${ }^{12}{ }^{18-21}$ It has been suspected that these membranes covering the TM would cause outflow reduction later, leading to treatment failure. Moreover, the remarkable disruption of the TM and accumulation of tissue debris in the juxtacanalicular region are thought to cause the acute IOP elevation seen in some patients after ALT treatment. ${ }^{15}$

Selective laser trabeculoplasty (SLT) is an alternative laser treatment introduced by Latina et al in 1995. ${ }^{22}$ SLT is a Q switched, frequency doubled Nd:YAG laser $(\lambda=532 \mathrm{~nm})$ that selectively targets the pigmented TM cells without adversely affecting the TM in vitro, rendering the TM architecture more preserved. ${ }^{22}$ There have been a number of studies that compared the efficacy of ALT and SLT based on posttreatment IOP reduction, and all reported that SLT is as effective as ALT in terms of IOP lowering. ${ }^{57}$ In general, both modalities lower IOP an average of $5 \mathrm{~mm}$ of mercury 6 months post-treatment. Furthermore, compared to ALT, SLT did not cause ablation craters at the border of pigmented and non-pigmented cells in the $\mathrm{TM}^{16}$ and the cellular changes induced by SLT did not extend beyond the Schlemm's canal ${ }^{17}$ as it would after ALT. In addition, SLT appears not to cause the membrane formed by migrating endothelial cells in the necrotic TM seen after ALT treatment. ${ }^{19}$ SLT allows the use of 80-100 times lower levels of energy and less laser spots on the TM, causing less damage to the TM. Based on the above observations and results, SLT appears to be less destructive and may be more repeatable clinically than ALT.

The focus of current SLT studies is SLT'S potential long term IOP reduction effect, predictors of SLT success and adverse events from SLT in the long term. There are already a number of studies devoted to observe immediate or monitor long term post-treatment IOP reduction; all concluded that SLT is able to maintain satisfactory IOP reduction within 6 months, ${ }^{5} 7^{2023-26}$ at 1 year, ${ }^{27-29}$ or longer ${ }^{28} 3031$ post-treatment. For example, 1 year IOP lowering seems to be maintained at around $5 \mathrm{~mm} \mathrm{Hg}$ from baseline. ${ }^{27}$ The most frequently used criterion for successful laser induced IOP lowering was a reduction of at least $20 \%$ from baseline prelaser IOP. On the other hand, regarding the predictors of SLT success, only one study attempted to determine the predictors of successful SLT. ${ }^{25}$ SLT's success rate varied from $40 \%$ to $84 \%$ in patient groups of different characteristics. ${ }^{2425282931}$ Thus, there could be indicators that predict

Abbreviations: ALT, argon laser trabeculoplasty; BCVA, best corrected visual acuity; IOP, intraocular pressure; $\mathrm{PI}$, peripheral laser iridotomy; SLT, selective laser trabeculoplasty; TM, trabecular meshwork 
better SLT outcome. Significantly higher IOP reduction was found in patients with $\geqslant 22 \mathrm{~mm} \mathrm{Hg}$ baseline IOP in a prospective non-randomised trial, ${ }^{32}$ but no prognostic importance of this finding has been suggested. Kano, et a $2^{25}$ discovered that lower baseline IOP is a significant success predictor, whereas factors such as, age, sex, previously failed ALT, and goniopigmentation were found to be non-significant. Similarly, Odberg and Sandvik ${ }^{6}$ indicated significantly higher risk for failure when a patient's baseline IOP was $\geqslant 32 \mathrm{~mm} \mathrm{Hg}$. Results of age and degree of angle pigmentation in relation to SLT success were mixed. ${ }^{20} 2531$

The objective of the present study is to determine the factors that predict successful SLT at 1 year post-treatment.

\section{MATERIALS AND METHODS}

Details of patient recruitment, materials, and methods are given in a previous publication of this study. ${ }^{53}$ Briefly, the study took place at the University of Ottawa Eye Institute and was approved by the Ottawa Hospital research ethics board. Potential study subjects were drawn from the patient pool of the institute's glaucoma clinic, from March 1997 to March 2003. Our inclusion criteria required the study patients to: (i) present with any type of open angle glaucoma including pseudoexfoliation and pigmentary glaucoma; (ii) have uncontrolled IOP of $\geqslant 16 \mathrm{~mm} \mathrm{Hg}$ with maximal medical therapy (three or more antiglaucoma drugs tolerated by the patient) or had failed previous 180/360 degree ALT treatment; (iii) be over 18 years of age; and (iv) have two sighted eyes. Subjects were excluded if s/he (i) had a type of glaucoma other than open angle; (ii) had advanced visual field defect; (iii) had any previous ocular surgery other than ALT or peripheral laser iridotomy (PI) done in the study eye, or required any ocular surgery within 6 months of this study enrolment; (iv) had cornea disease precluding accurate applantation tonometry; or $(\mathrm{v})$ was or would be on systemic steroids during the study period. All patients were required to sign the informed consent at enrolment. Follow ups were scheduled to take place at 1 week, 1, 3, 6, and 12 months after treatment. Intraocular pressure, best corrected visual acuity (BCVA), anterior chamber reaction, TM pigmentation grade, and number of medications used were recorded at all visits.

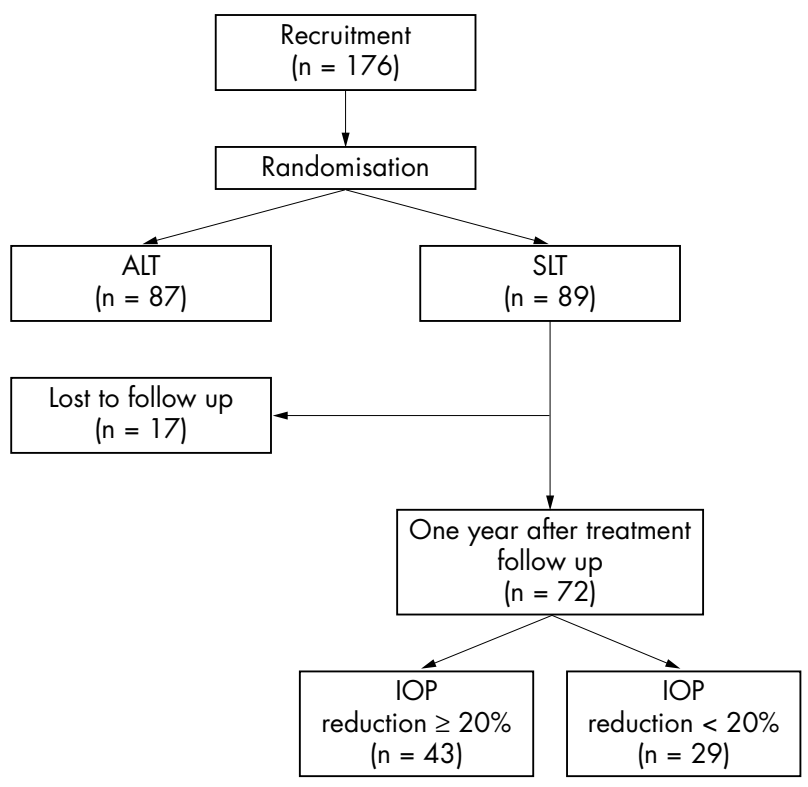

Figure 1 Outcome of randomisation and follow up to 1 year posttreatment.
A total of 176 patients were recruited and randomised in blocks of six using a computer generated random number list to receive either ALT or SLT. In the end, SLT was done in 89 randomised patients, who constituted the sample under study in this paper. Figure 1 gives the outcome of recruitment, randomisation, and follow up at 1 year post-treatment.

\section{Statistical analysis}

The primary outcome of interest was SLT induced IOP reduction; successful SLT was defined as having a reduction of $\geqslant 20 \%$ of pretreatment IOP at 1 year post-treatment. Best corrected visual acuity and IOP change between the "Success" and "Non-success" group were compared throughout the 1 year follow up period. Other potential predictors studied were age, sex, type of glaucoma, glaucoma risk factors, TM pigmentation, total energy used, and previous ALT. Distribution of these variables was compared between the success and non-success groups. For normal continuous variables, appropriate Student's $t$ tests were used to detect statistical significance; for categorical variables $\chi^{2}$ tests and the non-parametric Fisher's exact test; and for nominal categorical variables the Kruskal-Wallis test. Any covariates that achieved $\mathrm{p}<0.10$ for the bivariate analyses were included in the final multivariate logistic regression model. Multicollinearity was checked before determining the final model. All statistical analyses were performed using the Stata 7.0 software.

\section{RESULTS}

Out of the 89 patients who received SLT (table 1), 72 completed their 1 year follow up visit; 43 of which had achieved an IOP reduction of $\geqslant 20 \%$ from their baseline IOP. Seventeen patients were lost to follow up because of moving, unwillingness to return for further examinations, sickness, or death.

The success group has considerably higher baseline and 1 hour post-treatment IOP than the non-success group. There are no significant differences in the distribution of glaucoma risk factors and other prognostic factors except for hypertension and family history of glaucoma, which were only marginally significant between groups $(p<0.1)$ (table 2 ). Four out of the 72 patients $(6 \%)$, two in each outcome group

\begin{tabular}{ll} 
Table 1 & \multicolumn{1}{c}{ Baseline characteristics of the total study sample } \\
\hline Covariates & Value \\
\hline Age, mean (SD) (range) & $69.08(10.52)(36.57-88.37)$ \\
Sex (male/female) & $36 / 53$ \\
Glaucoma type, No (\%) & \\
OAG (POAG/OAG post PI/ & $54(60.67 \%)$ \\
post CE) & $23(25.84 \%)$ \\
PXG & $7(7.87 \%)$ \\
PG & $3(3.37 \%)$ \\
Combined mechanism & $2(2.25 \%)$ \\
Others & $23.84(4.88)(10,40)$ \\
Pretreatment IOP, mean (SD) (range) & $28 / 61$ \\
Previous ALT (Yes/No) & $20 / 85(20 / 20,20 / 800)$ \\
BCVA, median (range) & $16 / 67$ \\
Risk factors (Yes/No) & $2 / 81$ \\
Hypertension & $9 / 74$ \\
DM & $17 / 66$ \\
Myopia & $9 / 74$ \\
Family history & $14 / 69$ \\
Multiple & $39 / 44$ \\
Other & \\
Nil &
\end{tabular}

$\mathrm{OAG}$, open angle glaucoma; POAG, primary open angle glaucoma; $\mathrm{PI}$, peripheral iridotomy; $C E$, cataract extraction; $P X G$, pseudoexfoliation glaucoma; $P G$, pigmentary glaucoma; IOP, intraocular pressure; $B C V A$, best corrected visual acuity. 
Table 2 Comparison of the success and non-success groups (SD)

\begin{tabular}{|c|c|c|c|}
\hline \multirow[b]{2}{*}{ Covariate } & \multicolumn{2}{|c|}{ SLT success* at 1 year } & \multirow[b]{2}{*}{ p Value } \\
\hline & Yes & No & \\
\hline \multicolumn{4}{|l|}{ Continuous } \\
\hline Age (years) & $70.76(10.68)$ & $68.62(10.48)$ & 0.4047 \\
\hline Baseline IOP $(\mathrm{mm} \mathrm{Hg})$ & $26.05(4.82)$ & $20.97(2.85)$ & 0.0000 \\
\hline $\mathrm{IOP}(\mathrm{mm} \mathrm{Hg})$ at 1 hour post-treatment & $25.23(5.76)$ & $21.14(4.82)$ & 0.0024 \\
\hline Total energy (mJ) & $44.95(10.73)$ & $43.87(10.83)$ & 0.6825 \\
\hline \multicolumn{4}{|l|}{ Categorical } \\
\hline $\operatorname{Sex}(F / M)$ & $18 / 25$ & $12 / 17$ & 0.968 \\
\hline Glaucoma type (OAG/others) & $29 / 14$ & $17 / 12$ & 0.445 \\
\hline Previous ALT (Y/N) & $12 / 31$ & $7 / 22$ & 0.722 \\
\hline Other surgery during study $(\mathrm{Y} / \mathrm{N})$ & $20 / 19$ & $13 / 14$ & 0.802 \\
\hline Hypertension $(\mathrm{Y} / \mathrm{N})$ & $5 / 34$ & $9 / 20$ & 0.066 \\
\hline Diabetes mellitus $(\mathrm{Y} / \mathrm{N})$ & $1 / 38$ & $1 / 28$ & 0.831 \\
\hline Myopia (Y/N) & $3 / 36$ & $3 / 26$ & 0.504 \\
\hline Family history of glaucoma $(\mathrm{Y} / \mathrm{N})$ & $9 / 30$ & $2 / 27$ & 0.073 \\
\hline TM pigmentation (grade 1-4)† & 1256 & 955 & 0.489 \\
\hline BCVA (median) $\ddagger$ & $20 / 30$ & $20 / 30$ & 0.834 \\
\hline \multicolumn{4}{|c|}{$\begin{array}{l}\text { OAG, open angle glaucoma; } \mathrm{Y} / \mathrm{N} \text {, yes/no; TM, trabecular meshwork; BCVA, best corrected visual acuity } \\
\text { *SLT induced IOP reduction greater than or equal to } 20 \% \text { of pretreatment IOP. } \\
\text { †Kruskal-Wallis rank sum test. } \\
\text { fFisher's exact test for equality of median. }\end{array}$} \\
\hline
\end{tabular}

had an IOP spike defined as having $\geqslant 6 \mathrm{~mm} \mathrm{Hg}$ rise in IOP from baseline at 1 hour post-treatment.

The baseline IOP for the success group ranged from 18$36 \mathrm{~mm} \mathrm{Hg}$ and for the non-success group 16-28 mm Hg. A clear trend of steady post-treatment IOP reduction was observed in the success group, whereas in the non-success group there was no significant improvement in terms of IOP reduction throughout the 12 months (table 3 ). In both outcome groups, patients with lower baseline IOP had lower IOP at l year post-treatment (success: $p=0.0002$; nonsuccess: $p=0.0001)$. On the other hand, it was observed in the success group that patients with higher baseline IOP had significantly greater IOP reduction induced by SLT $(\mathrm{p}=0.00001)$, but not in the non-success group $(p=0.2292)$. The best corrected visual acuity was similar in both groups at baseline and throughout the 1 year follow up. As for the effect of previous ALT treatment, there is no significant difference in IOP regardless of the patients' success status at 1 year, except at 6 months post-treatment $(\mathrm{p}=0.0444)$.

Table 4 provides the simple and multivariate logistic models fitted to obtain the odds ratios (ORs) of the predictor variables. In simple logistic models, both baseline IOP and IOP at 1 hour post-treatment appeared to be significant predictors, but the significance of IOP at 1 hour posttreatment diminished in the multivariate model; multicollinearity was suspected, since baseline IOP and IOP at 1 hour post-treatment are highly correlated $(r=0.7865$, $\mathrm{p}=0.00001)$.

The final multivariate logistic model provided an OR of 1.58 for baseline IOP as a predictor of SLT success; the OR could be interpreted as given that other variables in the multivariate model were controlled for, for every $5 \mathrm{~mm} \mathrm{Hg}$ increase in baseline IOP, the odds of having successful SLT treatment outcome increases 10 times.

\section{DISCUSSION}

To the best of our knowledge, our study is the first highly successful SLT predictor study derived from high quality data of a randomised clinical trial. The results suggest that SLT success does not depend on age or sex. None of the glaucoma risk factors were found to be significant predictors. Family history of glaucoma was the closest to being significant, but since the analysis was not adequately powered to detect a difference, we cannot draw conclusions based on these data.

Interestingly, unlike ALT, TM pigmentation and type of glaucoma did not predict better outcome. Our results agree with previous findings that lower baseline IOP predicts lower post-treatment IOP, ${ }^{5}{ }^{25}$ and patients with higher baseline IOP benefit more from the laser treatment in terms of total IOP reduction..$^{32}$ Unlike previous studies where arbitrary cut offs of high baseline IOP were used in the analysis, we demonstrated a continuous relation between baseline IOP and post-treatment IOP reduction to be significant. Since our definition of success is based on the patients' relative response to the SLT treatment, we expect to observe most patients in the success group to have higher baseline IOP. As reported in the results section, the non-success group had a narrower range of baseline IOP than the success group, and all non-success patients had a baseline IOP of $<29 \mathrm{~mm} \mathrm{Hg}$; thus, the data might seem to indicate a regression towards the mean effect. However, the fact that even after all patients with IOP $\geqslant 30 \mathrm{~mm} \mathrm{Hg}$ at baseline were excluded in a separate analysis, the results still suggested that higher baseline IOP

Table 3 Post-treatment IOP* throughout the 1 year follow up period

\begin{tabular}{llll}
\hline $\begin{array}{l}\text { Post-treatment } \\
\text { follow up }\end{array}$ & $\begin{array}{l}\text { IOP reduction } \\
\mathbf{2 0 \%}\end{array}$ & $\begin{array}{l}\text { IOP reduction } \\
<\mathbf{2 0 \%}\end{array}$ & p Value \\
\hline 1 hour & $25.23(5.76)$ & $21.14(4.82)$ & 0.0024 \\
1 week & $21.08(5.76)$ & $20.14(4.79)$ & 0.2130 \\
1 month & $20.85(5.52)$ & $18.58(3.52)$ & 0.0655 \\
3 month & $19.41(5.47)$ & $18.46(3.88)$ & 0.4424 \\
6 month & $17.92(4.04)$ & $18.32(5.11)$ & 0.7217 \\
12 month & $16.60(3.39)$ & $20.00(5.78)$ & 0.0025 \\
\hline *Mean number (SD). & &
\end{tabular}


Table 4 Multivariate logistic regression analysis result

\begin{tabular}{llllll}
\hline $\begin{array}{l}\text { Models } \\
\text { Covariates } \\
\text { Odds ratio (95\% } \\
\text { confidence interval) }\end{array}$ & 1 & 2 & 3 & 4 & $\begin{array}{l}\text { Multivariate } \\
\text { Baseline IOP }\end{array}$ \\
$\begin{array}{l}\text { IOP at 1 hour } \\
\text { Hypertension }\end{array}$ & $1.47(1.2,1.8)$ & $1.16(1.0,1.3)$ & & & 5 \\
Family history & & $0.33(0.1,1.1)$ & & $1.58(1.2,2.1)$ \\
\hline
\end{tabular}

predicted better chance of SLT outcome in terms of posttreatment IOP reduction.

Our result regarding predictors of successful SLT are comparable to previous studies on successful ALT. Baseline IOP was found to correlate with IOP reduction post-ALT as well. ${ }^{34-37}$ Lower baseline IOP predicts lower post-ALT IOP, and higher baseline IOP predicts greater IOP reduction post-ALT. Interestingly, in ALT studies it was also found that presence of pseudoexfoliation,,$^{34}$ ALT performed as primary therapy, ${ }^{36}{ }^{38}$ grade of pigmentation, ${ }^{38}$ and number of preoperative antiglaucoma medications correlated with success. ${ }^{38}$ In our study previous ALT did not influence the success of SLT at 1 year.

\section{ACKNOWLEDGEMENTS}

This study was financially supported by the Coherent Medical Group.

\section{Authors' affiliations}

W G Hodge, K F Damii, W Rock, R Buhrmann, A M Bovell, Y Pan, Department of Ophthalmology, The University of Ottawa Eye Institute, 501 Smyth Road, Ottawa, Ontario, K1H 8L6 Canada

\section{REFERENCES}

1 Wise JB, Witter SL. Argon laser therapy for open angle glaucoma. Arch Ophthalmol 1979;97:319-22.

2 Wise JB. Glaucoma treatment by trabecular tightening with the argon laser. Int Ophthalmol Clin 1981;21:69-78.

3 Bylsma S, Samples J, Acott T, et al. Trabecular cell division after argon laser trabeculoplasty. Arch Ophthalmol 1988;106:544-7.

4 Bradley J, Anderssohn A, Colvis C, et al. Mediation of laser trabeculoplastyinduced matrix metalloproteinase expression by IL-1 $\beta$ and TNF $\alpha$. Invest Ophthalmol Vis Sci 2000;41:422-30.

5 Damii KF, Shah KC, Rock WJ, et al. Selective laser trabeculoplasty $v$ argon laser trabeculoplasty: a prospective randomized clinical trial. Br J Ophthalmol 1999;83:718-22.

6 Odberg T, Sandvik L. The medium and long-term efficacy of primary argon laser trabeculoplasty in avoiding topical medication in open angle glaucoma. Acta Ophthalmol Scand 1999;77:176-81.

7 Popiela G, Muzyka M, Szelepin L, et al. [Use of YAG-selecta laser and argon laser in the treatment of glaucoma] (abstract only; article in Polish). Klin Oczna 2000;102:129-33.

8 Agarwal H, Sihota R, T D. Role of argon laser trabeculoplasty as primary and secondary therapy in open angle glaucoma in Indian patients. Br J Ophthalmol 2002;86:733-6.

9 Martinez-de-la-Casa J, Garcia-Feijoo J, Castillo A, et al. Selective vs argon laser trabeculoplasty: hypotensive efficacy, anterior chamber inflammation, and postoperative pain. Eye 2004; 18:498-502.

10 Ritch R, Liebmann J, Robin A, et al. Argon laser trabeculoplasty in pigmentary glaucoma. Ophthalmology 1993;100:909-13.

11 Shingleton BJ, Richter CU, Dharma SK, et al. Long-term efficacy of argon lase trabeculoplasty. A 10-year follow-up study. Ophthalmology 1993; 100:1324-9.

12 Koller T, Sturmer J, Reme C, et al. Membrane formation in the chamber angel after failure of argon laser trabeculoplasty: analysis of risk factors. Br J Ophthalmol 2000;84:48-53.

13 Weber PA, Burton GD, Epitropoulos AT. Laser trabeculoplasty retreatment. Ophthalmic Surg 1989;20:702-6.

14 Feldman RM, Katz $\amalg$, Spaeth GL, et al. Long-term efficacy of repeat argon laser trabeculoplasty. Ophthalmology 1991;98:1061-5.
15 Melamed S, Pei J, Epstein D. short-term effect of argon laser trabeculoplasty in monkeys. Arch Ophthalmol 1985;103:1546-52.

16 Kramer T, Noecker R. Comparison of the morphologic changes after selective laser trabeculoplasty and argon laser trabeculoplasty in human eye bank eyes. Ophthalmology 2001;108:773-9.

17 Cvenkel B, Hvala A, Drnovsek-Olup B, et al. Acute ultrastructural changes of the trabecular meshwork after selective laser trabeculoplasty and low power argon laser trabeculoplasty. Lasers Surg Med 2003;33:204-8

18 Alexander R, Grierson I. Morphological effects of argon laser trabeculoplasty upon the glaucomatous human meshwork. Eye 1989;3:719-26.

19 Hollo G. Argon and low energy, pulsed Nd:YAG laser trabeculoplasty. A prospective, comparative clinical and morphological study. Acta Ophthalmol Scand 1996;74:126-31.

20 Latina M, Sibayan S, Shin D, et al. Q-switched 532-nm Nd:YAG laser trabeculplasty (selective laser trabeculoplasty): a multicenter, pilot, clinical study. Ophthalmology. 1998;105: 2082-8; discussion 2089-90).

21 Hollo G. Membrane formation in the chamber angle after failure of argon laser trabeculoplasty. Br J Ophthalmol 2000;84:673-4.

22 Latina MA, Park C. Selective targeting of trabecular meshwork cells: in vitro studies of pulsed and CW laser interactions. Exp Eye Res 1995:60:359-71.

23 Latina $M$, Tumbocon J. Selective laser trabeculoplasty: a new treatment option for open angle glaucoma. Curr Opin Ophthalmol 2002;13:94-6.

24 Chen E, Golchin s, Blomdahl S. A comparison between 90 degrees and 180 degrees selective laser trabeculoplasty. J Glaucoma 2004;13:62-5.

25 Kano K, Kuwayama Y, Mizoue S, Ito N. [Clinical results of selective laser trabeculoplasty] (abstract only; article in Japanese). Nippon Ganka Gakkai Zasshi 1999:103:612-16.

26 Kajiya S, Hayakawa K, Sawaguchi S. Clinical results of selective laser trabeculoplasty. Jpn J Ophthalmol 2000;44:574-5.

27 Gracner T. Intraocular pressure response of capsular glaucoma and primary open-angle glaucoma to selective $\mathrm{Nd}$ :YAG laser trabeculoplasty: a prospective, comparative clinical trial. Eur J Ophthalmol 2002;12:287-92.

28 Gracner T, Pahor D, Gracner B. [Efficacy of selective laser trabeculoplasty in the treatment of primary open-angle glaucoma] Klin Monatsbl Augenheilkd 2003;220:848-52

29 Cvenkel B. One-year follow-up of selective laser trabeculoplasty in openangle glaucoma. Ophthalmologica 2004;218:20-5.

30 Melamed S, Ben Simon G, Levkovitch-Verbin H. Selective laser trabeculoplasty as primary treatment for open-angle glaucoma: a prospective, non-randomized pilot study. Arch Ophthalmol 2003;121:956-60.

31 Kaulen P, Richter A, Wiemer C. Selective laser trabeculoplasty - results during the first two years. 97th Annual Meeting of the German Ophthalmology Society. Berlin. 1999:K14

32 Rubin MP, Lafayette SR, Albanis CV, et al. Pre-operative pressure as a significant determinant of SLT efficacy-The University of Chicago SLT Study. ARVO. Fort Lauderdale, 2004.

33 Damii KF, Bovell AM, Hodge WG. Selective laser trabeculoplasty: a review and comparison to argon laser trabeculoplasty. Ophthalmic Practice 2003;21:54-8.

34 Brooks AM, Gillies WE. Do any factors predict a favourable response to laser trabeculoplasty? Aust J Ophthalmol 1984;12:149-53.

35 Bergea B. Some factors affecting the intraocular pressure reduction after argon laser trabeculoplasty in open-angle glaucoma. Acta Ophthalmol (Copenh) 1984;62:696-704.

36 Tuulonen A, Airaksinen PJ, Kuulasmaa K. Factors influencing the outcome of laser trabeculoplasty. Am J Ophthalmol 1985;99:388-91.

37 Traverso CE, Rolando M, Calabria G, et al. Eye parameters influencing the results of argon laser trabeculoplasty in primary open-angle glaucoma. Ophthalmologica 1987; 194:174-80

38 Rouhiainen $\mathrm{H}$, Leino $M$, Terasvirta $M$. The effect of some treatment variables on long-term results of argon laser trabeculoplasty. Ophthalmologica 1995:209:21-4.

39 Rouhiainen HJ, Terasvirta ME, Tuovinen EJ. The effect of some treatment variables on the results of trabeculoplasty. Arch Ophthalmol 1988; 106:611-13. 